\title{
A Systematic Reconstruction of Brentano's Theory of Consciousness
}

\author{
Andrea Marchesi ${ }^{1}$ iD \\ Accepted: 19 November 2020 / Published online: 8 February 2021 \\ (c) The Author(s) 2021
}

\begin{abstract}
In recent years, Brentano's theory of consciousness has been systematically reassessed. The reconstruction that has received the most attention is the so-called identity reconstruction. It says that secondary consciousness and the mental phenomenon it is about are one and the same. Crucially, it has been claimed that this thesis is the only one which can make Brentano's theory immune to what he considers the main threat to it, namely, the duplication of the primary object. In this paper, I argue that the identity reconstruction is untenable, and I defend an alternative, which I name the unity reconstruction. According to the unity reconstruction, secondary consciousness is a real part of the mental phenomenon it is about, and hence is distinct from it. I contend that this thesis does not in itself lead to the duplication of the primary object, and that what should be blamed is rather a controversial thesis about the intentional structure of secondary consciousness-a thesis which Brentano ultimately abandoned.
\end{abstract}

Keywords Consciousness $\cdot$ Franz Brentano $\cdot$ Intentionality $\cdot$ Mental contents $\cdot$ Mereology

\section{Introduction}

For the last couple of decades, there has been a renewed interest among philosophers of mind in the theory of consciousness elaborated by Franz Brentano (1838-1917). Two approaches can be distinguished. The first approach appeals to Brentano's intuitions in order to cope with current issues about consciousness. ${ }^{1}$ The second approach aims at giving a systematic reconstruction of Brentano's own theory. ${ }^{2}$ The two approaches are perfectly compatible, but still differ in nature. In this paper, I will follow the second one. Even though I will focus on Brentano's statements, I will not discuss them in chronological order, nor will I try to decide when Brentano changed his mind. From an exegetical point of view, all I intend to do is to identify the different interpretations of Brentano's account and decide which is the most faithful one. The goal is to discuss both their compatibility with other claims of Brentano and their theoretical implications.

The gist of Brentano's theory of consciousness is the claim of the "double relation of the mental" (Doppelbeziehung des Psychischen; Brentano 1995b, p. 27)—roughly, the

Andrea Marchesi

andrea.marchesi@sbg.ac.at

1 Department of Philosophy (KGW), University of Salzburg, Franziskanergasse 1, 5020 Salzburg, Austria claim that every mental phenomenon involves an intentional relation to something distinct from itself, and an intentional relation to itself. ${ }^{3}$ Accordingly, Brentano distinguishes between "primary object" and "secondary object" (e.g., Brentano 1995a, p. 98) and speaks of "primary consciousness" and "secondary consciousness" (e.g., Brentano 1995a, p. 121) respectively. Consider hearing a sound (Brentano's favourite example of an ordinary mental event): the sound is said to be the primary object of the hearing because, "according to its nature," it is "prior" to the hearing. The priority in question is explained by Brentano in terms of conceivability: a "presentation" (Vorstellung) of the sound without a presentation of the hearing is conceivable, whereas a presentation of the hearing without a presentation of the

\footnotetext{
${ }^{1}$ See, e.g., Hossack (2002), Kriegel (2003), Smith (2004) and Thomasson (2000).

${ }^{2}$ See, e.g., Borsato (2009a), Hossack (2006), Kriegel (2018a, b) and Textor (2006, 2017a, b). By "systematic reconstruction" I mean more or less what is commonly referred to as "rational reconstruction." This is to be contrasted with historical reconstruction in the following way: "The objective of historical reconstruction is 'fidelity' to the author in question. Though rational reconstruction also aims at fidelity, it must first of all be 'relevant,' that is, it should be done in such a way that the positions it explains are made available to be discussed by contemporary philosophers" (Taieb 2018, p. 194).

3 "Every consciousness, upon whatever object it is primarily directed, is concomitantly directed upon itself" (Brentano 1995b, p. 25).
} 
sound is not. Thus, Brentano says, our hearing is first and foremost directed towards the sound, and is directed towards itself only "incidentally and additionally."

Brentano's writings themselves show that the claim that there is a double relation stands in need of a systematic treatment. The systematic reconstruction of Brentano's theory that has received the most attention is what I refer to as the identity reconstruction (see, notably, Kriegel 2018a, b; Textor $2017 \mathrm{a}, \mathrm{b}$ ). It says that secondary consciousness and the mental phenomenon it is about are one and the same. Crucially, it has been claimed that this thesis is the only one that makes the theory immune to what Brentano considers the main threat to it, namely, the duplication of the primary object (see Textor 2017a, b). In Brentano's eyes, a theory of consciousness should not entail that we always perceive sounds, colours, and the like twice. In what follows, however, I argue that the identity reconstruction is untenable and defend an alternative one, which I call the unity reconstruction..$^{5}$ On this reconstruction, secondary consciousness is a real part of the mental phenomenon it is about, and hence is distinct from it. I contend that the thesis of the unity reconstruction does not in itself lead to the duplication of the primary object; what should be blamed is rather a controversial thesis about the intentional structure of secondary consciousness - $\mathrm{a}$ thesis that Brentano first introduces and then rejects, unlike the thesis that secondary consciousness is a real part of the mental phenomenon it is about, which he maintained throughout his career.

There are reasons to believe that an examination of this issue will yield something more than simply a possible advancement in Brentano scholarship. Indeed, a glance at the current literature is sufficient to see that the problems Brentano ran into in studying the anatomy of the mind might also threaten contemporary views such as higherorder theories and structured self-representationalism (see, e.g., Kriegel 2009; Rosenthal 2005), for, on such theories, states like hearing a sound are conscious in virtue of being the object of a second-order mental state.

The paper will proceed as follows. In Sect. 2, I focus on the claim of the double relation of the mental. In Sect. 3,
I identify and discuss three reconstructions of Brentano's theory: the identity reconstruction (Sect. 3.1), the constituency reconstruction (Sect. 3.2), and the unity reconstruction (Sect. 3.3). Section 4 is devoted to the threat of the duplication of the primary object. Section 5 suggests the moral which contemporary theorists should draw from the discussion.

\section{Preliminaries: The Double Relation Claim}

Let us start with the basics. In Psychology from an Empirical Standpoint (1874), Brentano distinguishes two senses of the term "conscious" (bewusst). In the active sense of the term (henceforth: conscious $_{a}$ ), $x$ is said to be consciousness of an object. In the passive sense (henceforth: conscious $_{p}$ ), $x$ is said to be an object of consciousness. ${ }^{6}$ Brentano's theory of consciousness is centred on two theses (see Brentano 1995a, Book 2). The first says that every mental phenomenon (or mental $a c t$ ) is conscious; ; the second says that every mental phenomenon is conscious $\mathrm{p}$. In this framework, Brentano puts forward the double relation claim (henceforth: DRC), which is at the core of his theory of consciousness:

(DRC) Every mental phenomenon involves an intentional relation to something distinct from itself and an intentional relation to itself.

Consider a mental phenomenon like hearing a sound: first, it involves an intentional relation to the sound, which is a physical phenomenon (see Brentano 1995a, passim); and second, it involves an intentional relation to itself. In Brentano's terms, the hearing has a "primary object," which is the sound, and a "secondary object," which is itself (see, e.g., Brentano 1995a, p. 98). Accordingly, Brentano also speaks of primary consciousness and secondary consciousness. Brentano's alternative name for secondary consciousness is "inner consciousness" (see especially Brentano 1995a, Book 2, chap. 2). This consciousness is (at least) ${ }^{7}$ twofold: it is not just a presentation of $x$, but it is also a judgement (Urteil) about $x .^{8}$

\footnotetext{
4 "We can say that the sound is the primary object of the act of hearing, and that the act of hearing itself is the secondary object. Indeed, temporally they both occur at the same time, but according to its nature, the sound is prior. A presentation of the sound without a presentation of the act of hearing would not be inconceivable, at least prima facie, but a presentation of the act of hearing without a presentation of the sound would be an obvious contradiction. The act of hearing appears to be directed toward sound in the most proper sense of the term, and because of this it seems to apprehend itself incidentally and additionally" (Brentano 1995a, p. 98; translation slightly modified).

5 The reconstruction that I will defend is not novel. That of Alfred Kastil (1951, p. 47), a disciple of Brentano, is similar.
}

\footnotetext{
6 "We use the term 'unconscious' in two ways. First, in an active sense, speaking of a person who is not conscious of a thing; secondly, in a passive sense, speaking of a thing of which we are not conscious" (Brentano 1995a, p. 79, note).

7 In fact, for the early Brentano secondary consciousness is threefold, for it is also an emotion (Gefühl) regarding $x$ (see, e.g., Brentano 1995a, p. 120). On this aspect, which I shall leave aside, I refer the reader to Kriegel (2017).

8 "The secondary relation is a presenting and a judging, [or] believing, which [is] simply assertoric, yet evident" (Brentano 1995b, p. 89).
} 
It should be noted that DRC is only a rough (i.e., nontechnical) formulation of Brentano's theory of consciousness. Moving from such a formulation, some scholars read Brentano's theory as follows (see, e.g., Borsato 2009a, pp. 52-54; Caston 2002, pp. 791-792): in hearing a sound, there are many consciousnesses involved, but only one mental phenomenon. They seem to mean that, while consciousnesses are individuated by their objects (i.e., if there are two objects, then there are two consciousnesses), mental phenomena are not individuated by their objects (one single mental phenomenon can have two objects). More formally, the two relevant claims can be stated as follows: if a consciousness $\mathrm{C}$ has $x$ as object, and a consciousness $\mathrm{C}^{\prime}$ has $y$ as object, and $x \neq y$, then $\mathrm{C} \neq \mathrm{C}^{\prime}$; by contrast, it is not the case that if a mental phenomenon M has $x$ as object, and a mental phenomenon $\mathrm{M}^{\prime}$ has $y$ as object, and $x \neq y$, then $\mathrm{M} \neq \mathrm{M}^{\prime}$. Borsato (2009a, pp. 52-54) fleshes out the second claim. He states that, although objects in general presuppose mental phenomena, secondary objects presuppose only the mental phenomenon through which primary objects appear. While two primary objects presuppose two mental phenomena, one primary object and one secondary object appear through one and the same mental phenomenon. Thus, secondary consciousness requires the performing of a mental act, but it is not itself a mental act.

It should be noted that the foregoing reconstruction is based on a semantic distinction between "consciousness" and "mental phenomenon" which is absent in Brentano's texts. Indeed, there are exegetical reasons for claiming that, for Brentano, "mental phenomenon" and "consciousness" are extensionally equivalent (see also Hossack 2006, pp. 40-41). He expressly states that "consciousness" is a "synonymous" (gleichbedeutend) expression for "mental phenomenon," 9 and defines primary and secondary consciousnesses as "partial phenomena" (Theilphänomene) ${ }^{10}$ An exposition of Brentano's theory which does not use the above-mentioned distinction is the following. In hearing a sound, two partial mental phenomena are involved, but only one total mental phenomenon is involved - and here one can replace "mental phenomenon" with "consciousness." As regards hearing a sound, one partial mental phenomenon is an outer perception (i.e., a perception of a physical

\footnotetext{
9 "We must have a case of the latter sort before us in the dispute about the meaning of the term 'consciousness,' if it is not to be viewed as mere idle quibbling over words. [...] I prefer to use it as synonymous with 'mental phenomenon,' or 'mental act"' (Brentano 1995a, p. 78).

10 "The consciousness of the primary object and the consciousness of the secondary object are not each a phenomenon per se; rather, they are partial phenomena of one and the same unitary phenomenon. [...] We interpreted them, and had to interpret them, as parts of a unified real being" (Brentano 1995a, p. 120; translation slightly modified).
}

phenomenon), the other partial mental phenomenon is an inner perception (i.e., a perception of a mental phenomenon), and the total mental phenomenon is the hearing. The upshot is that DRC deserves a refined formulation:

(DRC*) Every mental phenomenon like hearing a sound is a phenomenon which is composed of two partial mental phenomena: one is called primary consciousness, which involves an intentional relation to something distinct from the mental phenomenon, whereas the other is called secondary consciousness, which involves an intentional relation to the mental phenomenon itself.

How is DRC* to be presented in systematic terms? At a general level, the question is how to construe the relationships between primary consciousness, secondary consciousness, and phenomena such as hearing a sound. At a specific level, the question is how to interpret the claim that primary and secondary consciousness are to phenomena like hearing a sound as partial phenomena are to a total phenomenon. These are the key questions for those who would attempt a systematic reconstruction of Brentano's theory of consciousness.

\section{Three Reconstructions of Brentano's Theory}

The statements that Brentano makes can give rise to three different reconstructions of his theory of consciousness. This section aims to provide the details of each of these reconstructions and to identify their virtues and shortcomings. Let us call primary consciousness $C_{1}$, secondary consciousness $\boldsymbol{C}_{2}$, and the total mental phenomenon $\boldsymbol{M}$.

\subsection{The Identity Reconstruction}

Consider the following two statements from the Psychology. First, Brentano states that "[i]t is only by considering a mental phenomenon in its relation to two different objects that we dismember (zergliedern) it conceptually (begrifflich) into two consciousnesses" (Brentano 1995a, p. 98), that is, $\mathrm{C}_{1}$ and $\mathrm{C}_{2}$. Second, he states that "every mental act" can be "considered" (betrachtet) "under different aspects (Seite)" (Brentano 1995a, p. 119), that is, as $\mathrm{C}_{1}$ or as $\mathrm{C}_{2}$.

Focusing on these statements, Kriegel (2018a, b, pp. 28-43) proposes to read Brentano's account of consciousness in light of a Fregean concept of identity: one and the same mental phenomenon can be framed either as primary consciousness or as secondary consciousness. " $\mathrm{C}_{1}$ " and " $\mathrm{C}_{2}$ " would then be to the mental phenomenon as "Morning Star" and "Evening Star" are to the planet Venus. Though there are two senses, they have the same reference. Kriegel argues 
for his interpretation by invoking Brentano's mereology. $\mathrm{He}$ reads Brentano's first statement as follows: $\mathrm{C}_{1}$ and $\mathrm{C}_{2}$ are parts only in thought, that is, they are merely conceptual parts. ${ }^{11}$ Kriegel claims that this is what Brentano means when he states that $\mathrm{C}_{1}$ and $\mathrm{C}_{2}$ are "distinctional parts" or "divisives" (divisiva). Ultimately, Kriegel's dual-framing model is quite sophisticated (or "impressionistic", in his own words): on the one hand, $\mathrm{C}_{1}$ and $\mathrm{C}_{2}$ are meant to exist only as (partial) ways of framing a mental phenomenon, and as such - that is, as descriptions - they are not identical. On the other hand, $\mathrm{C}_{1}$ and $\mathrm{C}_{2}$ are meant to be (partial) descriptions of one and the same entity (the hearing, for example), and in this sense, they are identical. ${ }^{12}$ Since $\mathrm{C}_{1}$ and $\mathrm{C}_{2}$ make up $\mathbf{M}$ (indeed, Brentano never mentions further partial phenomena of $\mathbf{M}), \mathrm{C}_{1}=\mathrm{C}_{2}$ implies that $\mathrm{C}_{1}=\mathrm{C}_{2}=\mathbf{M}$.

The identity reconstruction is contentious, both from an exegetical and a systematic point of view. On the exegetical level, the identity reconstruction turns out to be based on a highly disputable reading of Brentano's mereology. ${ }^{13}$ Let us see why. Brentano (1933, 1995a, b) distinguishes between separable parts and distinctional parts, also called "divisives." A part $\alpha$ is separable (ablösbar) from a part $\beta$ if and only if $\alpha$ can continue to be real even if $\beta$ has ceased to be real (see, e.g., Brentano 1995b, pp. 15-17). If $x$ does not have separable parts, then $x$ is an element. However, elements can be said to have further parts; these are distinctional parts. Parts $\alpha$ and $\beta$ are distinctional parts with respect to each other if and only if $\alpha$ is not separable from $\beta$ and $\beta$ is not separable from $\alpha$. As an example of divisives, Brentano mentions the two halves of a mereological (non-physical) atom: in an atom, we can "distinguish" (unterscheiden) one half from the other, but we cannot separate the first half from the second, and vice versa (see, e.g., Brentano 1995b, pp. 23-24). Or better still: we can separate them only in thought. Now, the identity reconstruction is at odds with two laws of Brentano's mereology. The first law is that a part $\alpha$ of $x$ cannot be identified either with a part $\beta$ of $x$, or with $x .^{14}$

\footnotetext{
11 A very similar reading is defended by Textor (2017a, pp. 56-57, 2017b, pp. 115-130), though his reading is motivated by reflections on the duplication argument. I will discuss this argument in Sect. 4.

12 "We might therefore say, doubtless somewhat impressionistically, that qua regarded the awareness and the awareness-of-awareness are different, even though in and of themselves they are identical." (Kriegel 2018a, p. 92). Kriegel's reading is expressly inspired by Hugo Bergmann's (1908, p. 12). On the latter, $C_{1}$ and $C_{2}$ are "individually" (individuell) identical but "conceptually" (begrifflich) distinct.

13 On Brentano's mereology, see Baumgartner and Simons (1994) and Kriegel (2018a, pp. 85-90, 2018b, pp. 32-37). On Brentano's mereology of consciousness, see Albertazzi (2006, pp. 131-143), Borsato (2009b, pp. 39-44), Dewalque (2013, pp. 458-459), Giustina (2017, pp. 29-30), Kriegel (2018a, pp. 90-93, 2018b, pp. 37-40), and Marchesi (2019, pp. 138-140)

${ }^{14}$ More accurately, Brentano subscribes to the following theses.
}

Precisely on this basis, Brentano explicitly denies that $\mathrm{C}_{1}$ and $\mathrm{C}_{2}$ are identical. ${ }^{15}$ The second law is that distinctional parts or divisives are not parts only in thought (or merely conceptual parts), but rather are real parts - that is, parts in reality - which are separable only in thought ${ }^{16}$ Unlike what is envisaged by Kriegel's reconstruction, Brentano does not deny the real existence of divisives; rather, he denies the real separability of divisives. To some extent, Brentano's first statement lends itself to such a reconstruction: we can "dismember" $\mathbf{M}$ - that is, we can separate its parts—only "conceptually," that is, only in considering the two partial phenomena which are involved in it.

On the systematic level, the thesis of the identity reconstruction leads to (at least) two infelicitous consequences. To see the first one, consider Brentano's conception of the judgements of $\mathrm{C}_{2}{ }^{17}$ According to him, these judgements are always positive. In making a positive judgement about $x$, we acknowledge $x$, and thereby accept $x$ 's existence. By contrast, in making a negative judgement about $x$, we reject $x$, and thereby deny $x$ 's existence (see Brandl and Textor 2018). In Brentano's notation, "God+" expresses a positive judgement, namely, a judgement by which we acknowledge God,

\section{Footnote 14 (continued)}

First, if $x$ is a part of $y$, then $x \neq y$. Second, if $x$ and $z$ are parts of $y$, then $x \neq z$.

15 "And it is clear that such real identity never holds between our concurrent mental activities, and that it will never be found between the diverse aspects of the simplest mental acts which were differentiated earlier. [...] [A] divisive, which I distinguish as a part in a real thing, cannot be called identical with this thing and hence with the other divisives which can be distinguished in it. A divisive never stands in a relation of real identity with another which has been distinguished from it, for if it did it would not be another divisive but the same one" (Brentano 1995a, p. 124). It is worth pointing out that in this context Brentano opts for the term "divisive" instead of "part" only because he considers the latter equivocal; see Brentano (1995a, p. 121).

16 "In the blue spot one must therefore distinguish a particularity of colour and a particularity of place. These particularities are thus really (wirklich) contained in it, [they] are distinctional parts of them" (Brentano 1995b, p. 18; emphasis mine) and "The sensing of the colour and the concomitant sensing of this sensing are directed towards different objects. The present case is, in this respect, similar to those separable parts which we discerned earlier in the mental domain, like, e.g., seeing and hearing and simultaneous seeing of different parts of one and the same picture. Whereas the separation of the parts considered there can only be actual, the parts considered here can only be separated distinctionally. This is why, having referred to the former as actually separable mental parts, it was probably not wholly inappropriate to call the latter inseparable (distinctional) ones" (Brentano 1995b, p. 27; translation slightly modified).

17 Brentano's theory of judgement is peculiar in that it does not take judgements to be propositional attitudes. According to Brentano, we judge (acknowledge or reject) things, not that things are thus-andso (see Textor 2006, p. 414, 2013, pp. 470-471; Brandl and Textor 2018). 
whereas "God-" expresses a negative judgement, namely, one by which we reject God (see Brentano 1956). Hence, $C_{2}$ is the mental phenomenon by which we acknowledge $\mathbf{M}$ (and thereby accept its existence). Now, suppose that you judge God negatively. In that case, $\mathrm{C}_{1}$ is a rejection (namely, $\mathrm{C}_{1}$ rejects something). So one may argue as follows: $\mathrm{C}_{1}=\mathrm{C}_{2} ; \mathrm{C}_{1}$ is a negative judgement; $\mathrm{C}_{2}$ is a positive judgement; therefore, $\mathrm{C}_{2}$ is at the same time a positive and a negative judgement. ${ }^{18}$ Since the third premise is part and parcel of Brentano's conception of $\mathrm{C}_{2}$ and the conclusion is absurd, the thesis of the identity reconstruction is false. For Brentano allows for the view that I can both acknowledge and reject one and the same $x$ at the same time-for example, when I mistrust my senses (see Brandl and Textor 2018)—but it does not allow for the view that one and the same $x$ can be at the same time both an acknowledgement and a rejection (see also Textor 2006, p. 423).

The second infelicitous conclusion to which the thesis of the identity reconstruction leads can be seen when considering the Brentanian view of inner perception. According to Brentano, this kind of perception is (self-)evident. On the epistemological level, that inner perception is evident means that the judgements of $\mathrm{C}_{2}$ cannot be false. ${ }^{19}$ On the ontological level, that inner perception is evident means that what is acknowledged by $\mathrm{C}_{2}$ is necessarily real (wirklich). ${ }^{20}$ Unlike the objects of inner perception, the objects of outer perception do not possess real existence; this is why Brentano calls outer perception "blind" (see, e.g., Brentano 1995a, p. 72). Now, some scholars (see Hossack 2006, pp. 52-54; Textor 2006, p. 422) have argued that the thesis of the identity reconstruction straightforwardly satisfies the claim that inner perception is (self-)evident. They reason as follows: on the epistemological level, if $\mathrm{C}_{2}=\mathbf{M}$, then trivially, the truth of the judgement of $\mathrm{C}_{2}$ is guaranteed; on the ontological level, if $\mathrm{C}_{2}=\mathbf{M}$, then trivially, if $\mathrm{C}_{2}$ is real then $\mathbf{M}$ is real. On a

\footnotetext{
18 Here I formalize an argument that was originally elaborated by Textor (2006, p. 424) against Soldati (2005, p. 68), who claims that as regards $\mathrm{C}_{2}$ and $\mathbf{M}$ "there are not two items to count." I take it for granted that if " $\mathrm{d}$ " and " $\mathrm{d} *$ " are two (partial) descriptions of one and the same entity, then if " $d$ is $F$ " is true, " $d^{*}$ is $F$ " is true as well. For example, if "The morning star is bright" is true, "The evening star is bright" is true as well.

19 "As everyone knows, memory is, to a great extent, subject to illusion, while inner perception is infallible and does not admit of doubt" (Brentano 1995a, p. 26) and "One gets into further difficulties if one takes into account in addition to outer perception, which is lacking in evidence, also inner perception, which admits of no illusion" (Brentano 2009a, p. 13).

20 "We said that mental phenomena are those phenomena which alone can be perceived in the strict sense of the word. We could just as well say that they are those phenomena which alone possess real existence as well as intentional existence. Knowledge, joy and desire really exist. Color, sound and warmth have only a phenomenal and intentional existence" (Brentano 1995a, p. 70).
}

closer look, however, this is not the case. Not only does the thesis of the identity reconstruction lead to unpalatable consequences, it also turns out to be incompatible with the evidence claim. This can be easily demonstrated. Recall that $\mathrm{C}_{2}=\mathbf{M}$ follows from $C_{1}=C_{2}$, and consider the case of hearing a sound. In such a case, $\mathrm{C}_{1}$ is blind. Again, a quick argument runs as follows: $\mathrm{C}_{1}=\mathrm{C}_{2} ; \mathrm{C}_{1}$ is blind; $\mathrm{C}_{2}$ is evident; therefore, $\mathrm{C}_{2}$ is at the same time evident and blind; therefore, $\mathrm{C}_{2}$ is at the same time evident and not evident, for evidence and blindness are mutually exclusive. Furthermore, by the principle of the indiscernibility of identicals, we conclude that $\mathrm{C}_{2}$ is not evident. ${ }^{21}$

\subsection{The Constituency Reconstruction}

Consider the following statement from the Psychology: $\mathrm{C}_{1}$ "contributes innerly to the being" of $\mathrm{C}_{2}$ (see Brentano 1995a, p. 98). If we translate Brentano's vague statement into the language of mereology, or better still, if we rephrase "contributes innerly to the being of" with "is part of," we obtain the thesis that $\mathrm{C}_{1}$ is part of $\mathrm{C}_{2}$. Taking inspiration from Textor (2006, p. 418), who calls this thesis the "constituency thesis," we can refer to the relative reconstruction as the constituency reconstruction. ${ }^{22}$ As Textor (2006, p. 420) puts it, the constituency reconstruction says that $\mathrm{C}_{1}$ is part of $\mathrm{C}_{2}$ and that both are distinctional parts of $\mathbf{M}$.

Admittedly, the thesis of the constituency reconstruction does not entail the worrisome consequences that the thesis of the identity reconstruction does. Consider again the case in which you judge God negatively. In such a case, $\mathrm{C}_{1}$ is a rejection. The constituency reconstruction allows for the following view: since $\mathrm{C}_{1}$ is part of $\mathrm{C}_{2}, \mathrm{C}_{1} \neq \mathrm{C}_{2}$ (by Brentano's mereology). Hence, a mental phenomenon (i.e., $\mathrm{C}_{1}$ ) is rejection, while another mental phenomenon (i.e., $\mathrm{C}_{2}$ ) is acknowledgement. For analogous reasons, the thesis at issue does not lead to the conclusion that one and the same $x$ is at the same time both evident and blind.

\footnotetext{
${ }^{21}$ Following Hossack (2006, pp. 54-55), who in turn moves from a Kimian notion of events, it may be argued on a non-Brentanian basis that the identity $C_{1}=C_{2}$ leads to another difficulty. One may reason as follows. An event is an instantiation of a certain relation in a certain order by certain particulars, and two events are identical if and only if exactly the same property or relation is instantiated by exactly the same things in exactly the same order. Now, let $C_{1}$ be the event of the perception of a sound $x$ by a subject $S$, and let $\mathrm{C}_{2}$ be the event of the perception of the hearing of $x$ by $S$. Let "p" express the perceptual relation and let "M" stand for the hearing in question. We write the two events as $\langle p, S, x\rangle$ and $\langle p, S, \boldsymbol{M}\rangle$ respectively. By the criterion for the identity of events, it follows that $x=\mathbf{M}$; but this is false, since the sound is not identical to the hearing.

22 " $[\mathrm{T}]$ he object of the higher-order act, i.e. the lower-order act, is one of its constituents. [...] [T] he higher-order presentation contains the lower-order presentation it is about [...]" (Textor 2006, pp. 418 419).
} 
At the systematic level, however, the constituency reconstruction turns out to be problematic. As has been already suggested, Brentano takes $\mathbf{M}$ to be a whole and $\mathrm{C}_{1}$ and $\mathrm{C}_{2}$ to be parts of that whole. Moreover, he assumes that $\mathbf{M}$ is made up of $\mathrm{C}_{1}$ and $\mathrm{C}_{2}$-in fact, he never mentions further partial phenomena of $\mathbf{M}$. In such a framework, the thesis of the constituency reconstruction leads to the acceptance of the real existence of wholes with only one part, for according to it, $\mathrm{C}_{1}$ is part of $\mathrm{C}_{2}$ and $\mathrm{C}_{2}$ is part of $\mathbf{M} \cdot{ }^{23}$ But a whole consisting of only one part is an absurdity ${ }^{24}$ : if there is a whole - $x$, say - then by definition there is a $y$ and a $z$ such that $y$ and $z$ are parts of $x$ and $y \neq z$. How are we to avoid ascribing to Brentano the absurd idea of a whole with only one part? We will see that shortly.

\subsection{The Unity Reconstruction}

What we are after is a reconstruction of the relationship between $\mathrm{C}_{1}, \mathrm{C}_{2}$, and $\mathbf{M}$. We are also aiming to develop a reconstruction which avoids implicitly ascribing to Brentano unpalatable claims. The only reconstruction which meets these requirements, I submit, is what I call the unity reconstruction. It holds that both $\mathrm{C}_{1}$ and $\mathrm{C}_{2}$ are real parts of $\mathbf{M}$. More accurately, it holds that $\mathrm{C}_{1}$ is part of $\mathbf{M}, \mathrm{C}_{2}$ is part of $\mathbf{M}$, and both are distinctional parts of $\mathbf{M}$.

From an exegetical point of view, the unity reconstruction turns out to be the best candidate to express Brentano's account of consciousness. For while the previous two reconstructions are mostly inferred from some (few!) statements by Brentano, the unity reconstruction is based on a claim that Brentano treats at length. Indeed, chapter 4 of Book 2 of the Psychology and chapter 2 of Descriptive Psychology (1887) are dedicated mainly to a systematic presentation of $\mathrm{C}_{1}$ and $\mathrm{C}_{2}$ as distinctional parts of the mental phenomenon in question.

From a systematic point of view, the unity reconstruction is not as problematic as the other two. First, the thesis of the unity reconstruction does not entail the worrisome consequences that the thesis of the identity reconstruction does. By describing the hearing as a (total) mental act which is composed of two (real) subacts-in other words, by stating that $\mathrm{C}_{1} \neq \mathrm{C}_{2}, \mathrm{C}_{1} \neq \mathbf{M}$, and $\mathrm{C}_{2} \neq \mathrm{M}$ - one can avoid saying that one and the same $x$ is at the same time both

\footnotetext{
23 On another occasion, Textor (2006, p. 420) seems to formulate a reading which is more intrepid than the foregoing one. He says not only that $\mathrm{C}_{1}$ is part of $\mathrm{C}_{2}$, but also that $C_{2}$ is part of $C_{1}$ (this latter assertion can also be found in Smith et al. 1982, p. 30). However, this is never stated by Brentano; what he repeatedly says is rather that $C_{2}$ is part of $\boldsymbol{M}$. Moreover, the view on which $x$ is part of $y$ and $y$ is part of $x$ is simply a further absurdity.

24 The absurdity of wholes with only one part is recognized in Textor (2017b, p. 127)
}

evident and blind, and that one and the same $x$ is at the same time both acceptance and denial. ${ }^{25}$ Second, the thesis of the unity reconstruction does not lead to the worrisome consequences that the thesis of the constituency reconstruction does. Unlike the latter, the thesis of the unity reconstruction does not say that $\mathrm{C}_{1}$ is to $\mathrm{C}_{2}$ as a part $\alpha$ of $x$ is to $x$; rather, it says that $\mathrm{C}_{1}$ is to $\mathrm{C}_{2}$ as a part $\alpha$ of $x$ is to a part $\beta$ of $x$. Thus, it does not lead us to the acceptance of the real existence of a whole with only one part.

To get a better grasp of the kind of relationship involved when considering hearing a sound from the point of view of the unity reconstruction, we have to distinguish between the relationships that are part-whole relationships and those that are not part-whole relationships. The first group includes the relationship between $C_{1}$ and $\boldsymbol{M}$ (for the consciousness of the sound is part of the hearing) and the relationship between $C_{2}$ and $\boldsymbol{M}$ (for the consciousness of the hearing is part of the hearing). The second group includes the relationship between the secondary object of $M$ and $\boldsymbol{M}$ (for the secondary object of the hearing is the hearing itself), the relationship between the primary object of $M$ and $\boldsymbol{M}$ (for the sound is not part of the hearing), ${ }^{26}$ the relationship between $C_{1}$ and $C_{2}$ (for the consciousness of the sound is not part of the consciousness of the hearing and the consciousness of the hearing is not part of the consciousness of the sound), the relationship between the object of $C_{1}$ and $C_{1}$ (for the sound is

\footnotetext{
25 Another question is whether the thesis of the unity reconstruction also satisfies the claim that inner perception is evident (for example, the claim that if we perceive hearing a sound, then we hear a sound) Brentano (1995a, p. 109) himself calls for a model of the evidence of inner perception. In this regard, one may say that the thesis of the unity reconstruction does not guarantee enough. The reasons for this are as follows. True, divisives are not really separable: whenever $C_{1}$ is there, $\mathrm{C}_{2}$ is there, and vice versa. Still, such a claim does not rule out that we can conceive of $\mathrm{C}_{2}$ without $\mathrm{C}_{1}$-and hence without $\mathbf{M}$. Indeed, divisives are separable in thought. In other words, the view of $\mathrm{C}_{1}$ and $\mathrm{C}_{2}$ as divisives of $\mathbf{M}$ does not imply that $\mathrm{C}_{2}$ entails the real existence of $\mathbf{M}$. But such an entailment is exactly what one needs to satisfy the evidence claim. In Brentano's (2009b, p. 89) words: “A man can be said to have direct, affirmative, and therefore factual evidence concerning the existence of a thing only if it would be contradictory to say that, although he is thinking of the thing, the thing does not exist." Now, for all that the thesis of the unity reconstruction says, a sentence like " $\mathrm{C}_{2}$ is real and $\mathrm{C}_{1}$ is not real" is not a contradiction. In order to satisfy the evidence claim, one could claim that $\boldsymbol{M}$ is part of $\boldsymbol{C}_{2}$, for as Brentano (1995a, p. 71) himself recognizes, the real existence of $x$ entails the real existence of all the parts of $x$. However, the thesis of the unity reconstruction does not say that $\mathbf{M}$ is part of $\mathbf{C}_{2}$. In conclusion, the thesis of the unity reconstruction does not violate the claim that inner perception is evident (for it does not say that $\mathrm{C}_{2}$ is conceivable without $\mathbf{M}$ ), but does not satisfy it either.

${ }^{26}$ For Brentano, the sound is part of the hearing only in a "modified" (i.e., improper) sense. In Brentanian mereology, $x$ is a part of $y$ if and only if $x$ is properly (i.e., really) in $y$; by contrast, $x$ is a part of $y$ in a modified sense if and only if $x$ is not properly (i.e., not really) in y. See especially Brentano (1995b, pp. 28-30), Borsato (2009b, pp. 39-44), and Marchesi (2019, p. 138).
} 
not part of the consciousness of the sound), and the relationship between the object of $C_{1}$ and $C_{2}$ (for the sound is not part of the consciousness of the hearing). In the next section, I shall explore this last relationship.

\section{The Threat of the Duplication of the Primary Object}

The usual view in the scholarly literature is that Brentano's master argument for his theory of consciousness is an infinite regress argument (see, e.g., Hossack 2006, pp. 38-39; Kriegel 2003, p. 111; Smith 1986, p. 149). According to this received view, Brentano argues roughly as follows: if a certain relationship between $\mathrm{C}_{1}, \mathrm{C}_{2}$, and $\mathbf{M}$ did not holdnamely, if they were not identical or at least suitably unified-then we would face an infinite regress of mental phenomena, which is plausibly assumed to be an intolerable result. Yet, as Textor (2017a, p. 55) acutely notes, Brentano's first concern in developing a theory of consciousness is not the threat of infinite regress, but rather what we call-somewhat impressionistically - the threat of the duplication of the primary object. ${ }^{27}$ Accordingly, Brentano's master argument for his theory of consciousness is the so-called duplication argument.

Here is the duplication argument unpacked (see also Textor 2017a, pp. 55-56 for a similar reconstruction). Assume that $\mathrm{C}_{1}$ and $\mathrm{C}_{2}$ are distinct entities, and hence are two consciousnesses:

(i) $\mathrm{C}_{1} \neq \mathrm{C}_{2}$

(ii) If $x$ is conscious ${ }_{p}$ both in $\mathrm{C}$ and $\mathrm{C}^{\prime}$, and $\mathrm{C} \neq \mathrm{C}^{\prime}$, then $x$ is conscious $\mathrm{p}_{\mathrm{p}}$ twice

(iii) The sound is conscious $\mathrm{p}_{\mathrm{p}}$ both in $\mathrm{C}_{1}$ and $\mathrm{C}_{2}$

(iv) $\therefore$ The sound is conscious p $_{\mathrm{p}}$ twice [from (i), (ii), and (iii)]

Since Brentano takes (iv) to be contrary our experienceindeed, we perceive the sound only once-he has to identify a culprit. According to Textor (2017a, b), Brentano rejects (i). In other words, he holds that Brentano's way out to the problem of the duplication of the primary object is the thesis of the identity reconstruction: $\mathrm{C}_{1}$ and $\mathrm{C}_{2}$ are the same mental phenomenon. He also holds that the thesis of the identity

\footnotetext{
27 Both the infinite regress problem and the problem of the duplication of the primary object concern something contrary to experience, but they are orthogonal with respect to each other: a theory of consciousness can run into the former without running into the latter, and vice versa. On the Brentanian theory of consciousness and the infinite regress problem, see Küng (1978, pp. 172-174), Textor (2006, pp. 424-430), and Marchesi (2019, pp. 140-145).
}

reconstruction is the only thesis which allows us to avoid the duplication. ${ }^{28}$

Three questions are in order. First: does Brentano avoid the threat of the duplication of the primary object by resorting to the thesis of the identity reconstruction? Second: can Brentano avoid this threat? Third: is the thesis of the identity reconstruction the only thesis which avoids this threat? Before answering these questions, let us examine all the premises of the duplication argument.

First, premise (i). In opening the discussion about the threat of duplication, ${ }^{29}$ Brentano poses the following question: as regards hearing, do we have many (and diverse) consciousnesses? His reply is sophisticated: if we want to determine the number (and variety) of consciousnesses according to the number (and variety) of mental phenomena, then the answer is no; but if we want to determine the number (and variety) of consciousnesses according to the number (and variety) of objects, then the answer is yes. This reply can be reconciled with DRC/DRC*: in answering no, Brentano wants to say that the hearing, as a total mental phenomenon, is only one consciousness; in answering yes, Brentano wants to say that $\mathrm{C}_{1}$ and $\mathrm{C}_{2}$, as partial mental phenomena of the hearing, are two consciousnesses. This complies with the

\footnotetext{
28 "'Hearing tone $F$ ' and 'awareness of hearing tone $F$ ' express different concepts of the same act. The act has two objects: the tone and itself. Each concept conceptualises the act with respect to one these objects: namely as awareness of the note (hearing) and as awareness of itself (awareness of hearing). The concepts are not concepts of two distinct acts that are parts of one complex act. For otherwise the note $F$ were [sic] presented twice: once in the subact hearing tone $F$ and then again in the subact awareness of hearing tone $F$." (Textor 2017a, p. 56) and "Which lesson can we draw from the Duplication Argument? It shows that hearing $F$ and awareness of hearing $F$ are the same mental act. [...] The act is not the result of a combination of distinct acts each of which refers to one particular thing. If it were, the double presentation problem would arise" (Textor 2017b, pp. 115, 117).

29 "Now the question arises, in such a case, do we have many and diverse presentations or only a single one? Before answering this question we must become clear about whether we want to determine the number and the variety of presentations according to the number and variety of objects, or according to the number of mental acts in which the objects are presented. On the first alternative it is clear that we must say that in the case under consideration we would have many presentations and that they are of different kinds; so much so that one of them constitutes the content of another, while having a physical phenomenon as its own content. If this were true, the physical phenomenon must, to a certain extent, belong to the content of both of these presentations, to that of one as its explicit object, to that of the other as, so to speak, its implicit object. It would seem, therefore, as Aristotle also noted, to turn out that the physical phenomenon must be presented twice. Yet this is not the case. Rather, inner experience seems to prove undeniably that the presentation of the sound is connected with the presentation of the presentation of the sound in such a peculiarly intimate way that its being at the same time contributes innerly to the being of the other." (Brentano 1995a, pp. 97-98; translation slightly modified).
} 
mereological assumptions on which the thesis of the unity reconstruction relies: $\mathrm{C}_{1}$ and $\mathrm{C}_{2}$ are conceived of as divisives (of the mental phenomenon), and a divisive of $x$ cannot be identical either with $x$ or with another divisive of $x$.

Now consider (ii). It is a major premise that can also be phrased as follows: if a consciousness $\mathrm{C}$ has $x$ as object, and a consciousness $\mathrm{C}^{\prime}$ has $x$ as object, and $\mathrm{C}$ and $\mathrm{C}^{\prime}$ are two consciousnesses, then $x$ is presented twice. This premise is not stated explicitly by Brentano, but he (Brentano 1995a, p. 98) does explicitly contend that the conjunction of (i) and (iii) creates the duplication of the primary object. Why? Because he implicitly endorses (ii).

So we come to (iii). Brentano (1995a, p. 103) formulates it in two ways: first, he says that the object of $\mathrm{C}_{1}$ is "also presented" in $\mathrm{C}_{2}$; and second, he says that the object of $\mathrm{C}_{1}$ "also belongs to the content of" $\mathrm{C}_{2} \cdot{ }^{30}$ This latter formulation raises the question as to whether (iii) has to be read in mereological terms. That is: should we interpret it as saying that the object of $\mathrm{C}_{1}$ is part of $\mathrm{C}_{2}$ ? I contend that Brentano would answer negatively, for if the sound were a part of $\mathrm{C}_{2}$, then the real existence of $\mathrm{C}_{2}$ would entail the real existence of the sound (for in Brentano's mereology the real existence of $x$ entails the real existence of all of the parts of $x$; see Brentano 1995a, p. 71) However, this is not the case: when I hallucinate the sound, my consciousness of the (nonveridical) hearing really exists, but the sound does not really exist. What Brentano has in mind in this context, I take it, is not a content in a mereological sense, but rather a content in an intentional sense: the sound is the object of $\mathrm{C}_{1}$, but it is also the object of $\mathrm{C}_{2}$. We can also say that $\mathrm{C}_{2}$ has access both to $\mathbf{M}$ and to the primary object of $\mathbf{M}$, and name (iii) the double access claim. (For the sake of clarity, " $x$ has access to $y$," " $y$ is the object of $x$," and " $y$ is conscious in $x$ " are synonymous expressions).

At this stage, a brief systematic analysis of the double access claim is in order. It has been rightly observed that it is a debatable claim and therefore in need of argument (see Textor 2017a, p. 56). One is tempted to derive it as follows. Since $\mathrm{C}_{2}$ is directed towards $\mathbf{M}$ in its totality (see, e.g., Brentano 1995a, p. 100), and $\mathrm{C}_{1}$ is a (distinctional) part of $\mathbf{M}$ (by the thesis of the unity reconstruction), then $\mathrm{C}_{2}$ is also directed towards $\mathrm{C}_{1}$-assuming that the consciousness of $\mathbf{M}$ is also directed towards the parts of $\mathbf{M} .{ }^{31}$ One could next

\footnotetext{
30 "If we see a colour and have a presentation of our act of seeing, the colour which we see is also presented in the presentation of the seeing. This colour is a content of the act of seeing, but it also belongs to the content of the presentation of the act of seeing." (Brentano 1995a, p. 103; translation slightly modified; emphasis mine).

31 On the same basis, one could infer that $\mathrm{C}_{2}$ is also directed towards itself. Following Fréchette (2018), we can call such directedness "joint self-direction." Textor (2017b, pp. 120-121) models joint self-direction on the structure of plural demonstratives. For example, in saying "We will be late," I am referring to a group of people
}

point out that the consciousness of the consciousness of a sound is a presentation of the presentation of a sound and recall that a presentation of the presentation of a sound is inconceivable without a presentation of the sound - a thesis that Brentano (1995a, p. 98) himself endorses. Indeed, one cannot think about a thought about the sound without also thinking about the sound. From all this, one could try to conclude that $\mathrm{C}_{2}$ is also directed towards (i.e., about) the sound. The argument, however, will not work. The fact that one cannot think about a thought about $x$ without also thinking about $x$ does not entail that the thought about the thought about $x$ is (also) about $x$ (i.e., that one and the same thought is about both the thought about $x$ and about $x$ ). Even granted that the existence of the presentation of the presentation of the sound entails the existence of the presentation of the sound, it does not follow that the presentation of the presentation of the sound is (also) about the sound.

Now on to the three questions mentioned above. As for the question whether Brentano avoids the threat of the duplication by resorting to the thesis of the identity reconstruction, one should note that he (Brentano 1995a, pp. 97-98) states that if $\mathrm{C}_{1}$ and $\mathrm{C}_{2}$ were not "connected" "in such a peculiarly intimate way" that the "being" of one "at the same time contributes innerly to the being of the other," then the sound would be conscious ${ }_{\mathrm{p}}$ twice - with respect to $\mathrm{C}_{1}$ as an "explicit (ausschliesslicher) object" and with respect to $\mathrm{C}_{2}$ as an "implicit (eingeschlossener) object." 32 Are these terms to be interpreted in the sense that Brentano's solution to the problem is the view that $\mathrm{C}_{1}$ and $\mathrm{C}_{2}$ are the same mental phenomenon - that is, the thesis of the identity reconstruction? Nothing seems to force us in such a direction. Indeed, Brentano's impressionistic words ("connection," "contribution") make us think rather of the other two theses we have considered, namely, the thesis of the constituency reconstruction and the thesis of the unity reconstruction.

So we come to our second question: whether Brentano can avoid the threat of duplication of the primary object. In this regard, one can easily see that neither the thesis of the constituency reconstruction nor the thesis of the unity reconstruction is a way out to the problem of duplication. Indeed, on both reconstructions, $\mathrm{C}_{1}$ and $\mathrm{C}_{2}$ turn out to be

\section{Footnote 31 (continued)}

one of whom is me. Analogously, $\mathrm{C}_{2}$ is a part of $x$ which is directed towards $x$ and itself together. In this regard, however, Marchesi (2019, pp. 142-143) points out that if one combines the thesis of the unity reconstruction with another thesis of Brentano's framework, namely, that the consciousness of $x$ is not identical to the consciousness of a part of $x$ (see, e.g., Brentano 1995b, p. 104), the relevant conclusions cannot be drawn.

${ }^{32}$ Compare Textor's (2017a, p. 56) formulation of the double access claim: " $S$ 's perceiving $S$ perceiving $x$ is directly of $S$ 's perceiving $x$ as well as indirectly of $x$. ." 
two consciousnesses. On the constituency reconstruction, since $\mathrm{C}_{1}$ is to $\mathrm{C}_{2}$ as a part of $x$ is to $x$, then $\mathrm{C}_{1} \neq \mathrm{C}_{2}$; on the unity reconstruction, since $\mathrm{C}_{1}$ is to $\mathrm{C}_{2}$ as a (distinctional) part $\alpha$ of $x$ is to a (distinctional) part $\beta$ of $x$, then $\mathrm{C}_{1} \neq \mathrm{C}_{2}$. And if $\mathrm{C}_{1}$ and $\mathrm{C}_{2}$ are two consciousnesses and the sound is conscious $_{\mathrm{p}}$ both in $\mathrm{C}_{1}$ and $\mathrm{C}_{2}$, then the sound is conscious $\mathrm{p}_{\mathrm{p}}$ twice. To avoid the duplication of the primary object, one could discard (i) or (ii) or (iii). However, there seems to be no way that any of them can be discarded, for (i) and (ii) are cornerstones of Brentano's theory, and (iii) is taken by the Brentano (1995a, p. 94) of the Psychology to be "evident" (einleuchtend). Of course, the thesis of the identity reconstruction would avoid the threat of duplication right away, but, as I have argued, it is not Brentano's theory. It seems therefore that Brentano cannot avoid what he takes to be the main threat to a theory of consciousness.

There is, however, a viable alternative, one that is offered by Brentano himself. In a later writing-specifically, a letter to Anton Marty dated March 17, 1905-he goes back to the intentional structure of the two partial consciousnesses in question. In this text, he proceeds negatively: he puts the emphasis on what $\mathrm{C}_{1}$ and $\mathrm{C}_{2}$ are not directed towards. Regarding $\mathrm{C}_{1}$, he states that its object is not what is referred to as "presented sound," but rather the sound itself. Regarding $\mathrm{C}_{2}$, he states that its object is not the sound, but rather what is referred to as "presented sound." ${ }^{33} \mathrm{I}$ do not have the space to elucidate the notion of "presented sound," 34 but for the present purpose, what matters is that such a view expressly denies that $\mathrm{C}_{2}$ also has access to the primary object of the relevant mental phenomenon. In Brentano's (2009b, p. 53) own words, "what are experienced as primary objects [...] are never themselves the objects of inner perception." Hence, on such a view, only one consciousness has access to the sound, and this consciousness is $\mathrm{C}_{1}$. This view is confirmed by a passage in Descriptive Psychology. Here Brentano (1995b, p. 27) compares and contrasts the case of $\mathrm{C}_{1}$ and $\mathrm{C}_{2}$ with the case of positive quality and evidence of the

\footnotetext{
33 "[T]he presentation of a horse does not have 'presented horse' as object $[\ldots]$, but rather 'horse' $[\ldots]$ The 'thought horse' considered as object would be the object of inner perception, which the thinker perceives whenever he forms a correlative pair consisting of this 'thought horse' along with his thinking about the horse; for correlatives are such that one cannot be perceived or apprehended without the other. But what are experienced as primary objects, or what are thought universally as primary objects of reason, are never themselves the objects of inner perception. [...] I would like to have it made clear that $[\ldots]$ I have always held (in agreement with Aristotle) that 'horse' and not 'thought horse' is the immanent object of those thoughts that pertain to horses. Naturally, however, I did say that 'horse' is thought by us, and that insofar as we do think of it (N.B., insofar as we think of the horse and not of the 'thought horse') we have 'horse' as (immanent) object' (Brentano 2009b, pp. 52-53; translation slightly modified).

34 On this, see Taieb (2018, esp. Section 3.2.3).
}

judgement "There is a truth," and writes that while in the latter case we find two parts which share an object- that is, they are directed towards one and the same thing, namely, the truth-in the former we do not. In such a framework, (iii) does not hold, and thus no vicious duplication arises.

We are finally in a position to answer our third question, namely: is the thesis of the identity reconstruction the only thesis that can protect Brentano's theory from the threat of the duplication of the primary object? The answer is no, for the thesis of the unity reconstruction in itself does not engender the duplication. For the duplication to arise, the view of $\mathrm{C}_{1}$ and $\mathrm{C}_{2}$ as distinct has to be coupled with the double access claim. At some point, Brentano rejects such a claim while still retaining the thesis of the unity reconstruction.

\section{Closing Remarks}

As I said in the introduction, the problems Brentano ran into in exploring the mind are also problems that contemporary views might face. In particular, they may threaten views such as higher-order theories and structured self-representationalism. ${ }^{35}$ On both of these views, states like hearing a sound are conscious in virtue of being the object of a second-order mental state. And again on both views, a second-order mental state is distinct from a first-order mental state: on the self-representationalist variant, a second-order mental state and a first-order mental state are proper parts of a (complex) state; on the higher-order variant, the two states not only are distinct, but do not even form anything at all.

What is the moral these theorists should draw from a systematic reconstruction of Brentano's theory of consciousness-specifically, from a systematic reconstruction of the duplication argument? Unlike what has been suggested (see Textor 2017b, pp. 123-130), I think that the moral is not that the second-order state and the first-order state are to be conceived as one and the same-a view that faces several difficulties on its own (see, notably, Rosenthal 2005). The moral they should draw is rather, I submit, that they should avoid conceiving of the higher-order state as also directed towards the object of the lower-order state. As long as they do not commit themselves to such a view, their theory is not exposed to a vicious duplication of aboutness.

Acknowledgements I am grateful to the Austrian Science Fund (FWF), Grant No. M 2831, for generous financial support during the time this paper was written. I have presented some of these ideas at the workshop Mind and knowledge. Brentano, Husserl, and beyond (University of Salzburg, May 29, 2019). I would like to thank Johannes Brandl,

\footnotetext{
${ }^{35}$ I refer to the self-representational theory developed by Kriegel (2009) — the so-called "crooked representational account." For other variants of self-representationalism, see McClelland (2020).
} 
Guillaume Fréchette, Arnaud Dewalque, Hynek Janoušek, Robin Rollinger, and Hamid Taieb for the valuable feedback. Special thanks to the anonymous referees and the editors for Topoi, whose comments led to substantial improvements in the paper.

Funding Open Access funding provided by Paris Lodron University of Salzburg.

\section{Compliance with Ethical Standards}

Conflict of Interest The authors declare that they have no conflict of interest.

Open Access This article is licensed under a Creative Commons Attribution 4.0 International License, which permits use, sharing, adaptation, distribution and reproduction in any medium or format, as long as you give appropriate credit to the original author(s) and the source, provide a link to the Creative Commons licence, and indicate if changes were made. The images or other third party material in this article are included in the article's Creative Commons licence, unless indicated otherwise in a credit line to the material. If material is not included in the article's Creative Commons licence and your intended use is not permitted by statutory regulation or exceeds the permitted use, you will need to obtain permission directly from the copyright holder. To view a copy of this licence, visit http://creativecommons.org/licenses/by/4.0/.

\section{References}

Albertazzi L (2006) Immanent realism. An introduction to Brentano. Springer, Dordrecht

Baumgartner W, Simons P (1994) Brentano's mereology. Axiomathes 5:55-76

Bergmann H (1908) Untersuchungen zum Problem der Evidenz der inneren Wahrnehmung. Max Niemeyer, Halle

Borsato A (2009a) Innere Wahrnehmung und innere Vergegenwärtigung. Königshausen and Neumann, Würzburg

Borsato A (2009b) Ist das Erleben Teil des Erlebten? Phänomen Forsch 2009:37-59

Brandl J, Textor M (2018) Brentano's theory of judgement. In: Zalta EN (ed) The Stanford encyclopedia of philosophy. Center for the Study of Language and Information, Stanford University, Stanford

Brentano F (1933) Kategorienlehre. Meiner, Leipzig

Brentano F (1956) Die Lehre vom richtigen Urteil. Francke, Bern

Brentano F (1995a) Psychology from an empirical standpoint (Trans. L. MacAlister). Routledge, London

Brentano F (1995b) Descriptive psychology (Trans. B. Müller). Routledge, London

Brentano F (2009a) Philosophical investigations on space, time and the continuum (Trans. B. Smith). Routledge, London

Brentano F (2009b) The true and the evident (Trans. R. Chisholm). Routledge, London

Caston V (2002) Aristotle on consciousness. Mind 111:751-815
Dewalque A (2013) Brentano and the parts of the mental: a mereological approach to phenomenal intentionality. Phen Cog Sci 12:447-464

Fréchette G (2018) Review of “Brentano's mind.” In: Textor M (ed) Notre Dame philosophical reviews. University of Notre Dame, Notre Dame

Giustina A (2017) Conscious unity from the top down: a Brentanian approach. Monist 100:16-37

Hossack K (2002) Self-knowledge and consciousness. Proc Aristotelian Soc 102:163-181

Hossack K (2006) Reid and Brentano on consciousness. In: Textor M (ed) The Austrian contribution to analytic philosophy. Routledge, London, pp 36-63

Kastil A (1951) Die Philosophie Franz Brentanos. Bergland, Salzburg

Kriegel U (2003) Consciousness as intransitive self-consciousness: two views and an argument. Can J Philos 33:103-132

Kriegel U (2009) Subjective consciousness: a self-representational theory. OUP, New York

Kriegel U (2017) Brentano's classification of mental phenomena. In: Kriegel U (ed) The Routledge handbook of Franz Brentano and the Brentano school. Routledge, London, pp 97-102

Kriegel U (2018a) Brentano's dual-framing theory of consciousness. Philos Phenomen Res 97:79-98

Kriegel U (2018b) Brentano's philosophical system: mind, being, value. OUP, Oxford

Küng G (1978) Zur Erkenntnistheorie von Franz Brentano. Graz Phil S 5:169-181

Marchesi A (2019) Brentanian inner consciousness and the infinite regress problem. Dialectica 73:129-147

McClelland T (2020) Self-representational theories of consciousness. In: Kriegel U (ed.) Oxford handbook of philosophy of consciousness. OUP, Oxford

Rosenthal D (2005) Consciousness and mind. OUP, Oxford

Smith B et al (1982) Parts and moments. Studies in logic and formal ontology. Philosophia Verlag, Munich

Smith D (1986) The structure of (self-)consciousness. Topoi 5:149-156

Smith D (2004) Mind World. Essays in phenomenology and ontology. CUP, Cambridge

Soldati G (2005) Brentano on inner perception, intrinsic truth and evidence. In: Reicher ME, Marek J (eds) Experience and analysis. ÖBV \& HPT, Wien, pp 63-73

Taieb H (2018) Relational intentionality. Brentano and the Aristotelian tradition. Springer, Dordrecht

Textor M (2006) Brentano (and some neo-Brentanians) on inner consciousness. Dialectica 60:411-432

Textor M (2013) Brentano on the dual relation of the mental. Phen Cog Sci 12:465-483

Textor M (2017a) Brentano on consciousness. In: Kriegel U (ed) The Routledge handbook of Franz Brentano and the Brentano school. Routledge, London, pp 49-60

Textor M (2017b) Brentano's mind. OUP, Oxford

Thomasson A (2000) After Brentano: a one-level theory of consciousness. Eur J Philos 8:190-210

Publisher's Note Springer Nature remains neutral with regard to jurisdictional claims in published maps and institutional affiliations. 